\title{
PHYSICAL AND MECHANICAL PROPERTIES OF JOJOBA
} SEEDS

Matouk, A. M. *; M. M. El-Kholy ${ }^{* *}$ A. Tharwat ${ }^{*}$ and M. E. ElMenshawy*

${ }^{*}$ Agric. Eng., Dept. Fac. of Agric. Mansoura Univ., Egypt.

**Handling and processing of Agric. Crops Dept. Agric. Eng. Res. Institute.

\section{ABSTRACT}

A study was carried out to measure some of the most important physical and mechanical properties of freshly harvested jojoba seeds at initial moisture content of about $7 \% \pm 1$ (d.b). The studied physical properties included principal dimensions of jojoba seeds (length, width and thickness), geometric diameter, arithmetic diameter, shape index, seed volume, frontal area, arithmetic cross sectional area, surface area, surrounded surface area, sphericity, mass of 100 seeds, porosity, real density and bulk density (at loose and vibrated fill) . While the mechanical properties included, repose angle, seed hardness, shear force, crushing force and porosity of seeds. The obtained results showed that, the principal dimensions of jojoba seeds including length, width and thickness recorded values of $(16.95,13.13$ and $11.78 \mathrm{~mm}$ ) respectively. It was also recorded a volume of $1374.62 \mathrm{~mm}^{3}$, geometric diameter of $13.74 \mathrm{~mm}$, arithmetic diameter of $13.95 \mathrm{~mm}$, frontal area of $174.80 \mathrm{~mm}^{2}$ and a sphericity of $81.19 \%$. The real density of jojoba seeds was $976.86 \mathrm{~kg} / \mathrm{m}^{3}$. While, the bulk density recorded value of 602.10 and $630.33 \mathrm{~kg} / \mathrm{m}^{3}$ under loosely and vibrated fill conditions respectively. The repose angle of jojoba seeds recorded a value of $29^{\circ}$, seed hardness of $153.19 \mathrm{~N}$, shear force of $111.78 \mathrm{~N}$ at the longitudinal axis and 207.45 $\mathrm{N}$ at the transverse axis. The crushing forces of seeds were 302.95 and $295.25 \mathrm{~N}$ at the longitudinal and the transverse axis respectively. While, the recorded average of porosity was about $44.88 \%$. Mass of hundred seeds ranged from $(99.15$ to $109.20 \mathrm{~g}$ ) with on average of $103.79 \mathrm{~g}$.

\section{INTRODUCTION}

Oil seeds crops and their products are the most valuable agricultural crops in the world trade (Kadharmestan et. al., 1997). Sun flower, maize, soybean, and canola considered as the most important oilseed crops in Egypt. However during the last few years new seed crops such as jojoba has been introduced to the Egyptian agriculture as promising industrial crop (Ministry of Agriculture Statistics, 2007).

Jojoba [Simmondsia chinensis] belongs to the family simmondsiaceae is considered one of the new industrial oil seed crops. Selection over years has produced clones having potential seed yield of 3-4 ton per ha. Some of these clones are currently being planted in large areas in different countries (Melthorpe, 1998; and Tobares, et al., 2004).

In Egypt the area planted with jojoba is over 762 fed. annually produce about 180 ton seeds and its plantations are concentrated in Ismailia and south Sinai governorates (Ministry of Agriculture Statistics, 2007). Regardless of the forecited economic benefits of jojoba plant products, planting jojoba shrubs in Egypt has a promising future specially because of its low water requirements and its high tolerance to salinity, as well as its ability to be planted in the new reclaimed lands or uncultivated ones. The 
fruit of jojoba plant is a capsule of tan or brown color at maturation stage. It contains one to three dark brown seeds; at maturity, most of them vary in size and weight from 700 to 3500 seeds $/ \mathrm{kg}$, (Hogan et al., 1980).

Oil crops such as Jojoba are processed into products derived by a partial removal of one of the major seed components, so it is important to understand the physical and mechanical characteristic of oil seeds that governing their response with the machines, processes, and handling operation which can be designed for maximum efficiency and highest quality of the end product. Meanwhile, the increasing economic important of oilseed crops together with complexity of modern technology for their production, handling, storage, processing, preservation, quality evaluation, distribution and marketing demands a better knowledge of the physical and mechanical properties of these materials ( EL-Sahrigi, 1997; Matouk et al., 2002) .

Many of research studies on physical and mechanical properties of the traditional oil seed crops such as maize, sunflower, soybeans, sesame, and canola have been conducted by Egyptian researchers (Owies, 1995; ElSahrigi, 1997; Matouk et. al., 2002; Tharwat, 2007). However limited studies were conducted on the new oil seed crops such as jojoba.

The main goal of the present study is to determine some of the most important physical and mechanical properties of jojoba seeds as a new and promising oil seed crop for Egyptian industry, beside the importance of these properties in the process of oil extraction.

\section{MATERIALS AND METHODS}

Materials:

Freshly harvested jojoba seeds used for the experimental work were harvested from the farm of jojoba trees ( $90 \mathrm{~km}$ from Cairo, Alex. desert road) at moisture content of about $7 \% \pm 1$ (d.b). The collected jojoba seeds were kept in plastic bags and stored temporarily in a freezer adjusted at temperature of $\left(-5^{\circ} \mathrm{C}\right)$ in order to suppress fungal growth and minimize quality changes.

Equipments, Measurements and Test Procedure:

Before each experiment, jojoba samples were taken out from the freezer and left at room temperature until the initial temperature of the seeds approached a level (at or around) that of the ambient temperature.

Measuring of physical and mechanical properties of jojoba seeds were carried out according to the following procedure.

\section{Physical Properties}

Physical properties of jojoba seeds included seed principal dimensions and related characteristics, mass of 100 seeds, the projection area, bulk and true density and porosity.

\section{a - Moisture content of Jojoba seeds:}

The oven drying method was used for determining moisture content of seeds. Five grams of jojoba seeds were crushed and then placed inside the oven at $130 \pm 2{ }^{\circ} \mathrm{C}$ until a constant weight was reached (based on Preliminary study on the crop ), and then kept in a desecrator at the room temperature. The dried samples were weighed again using an electronic 
digital balance and the moisture content of seeds was calculated in dry bases.

b - Seed dimensions:

A digital caliper model (Mitutoyo DAG-500, Japan) shown in figure (1) with accuracy of $0.01 \mathrm{~mm}$, was used to measure the principal dimensions of jojoba seeds length (L), width (W) and thickness (T) in millimeters and the average Length, width and thickness of 100 seeds were considered.

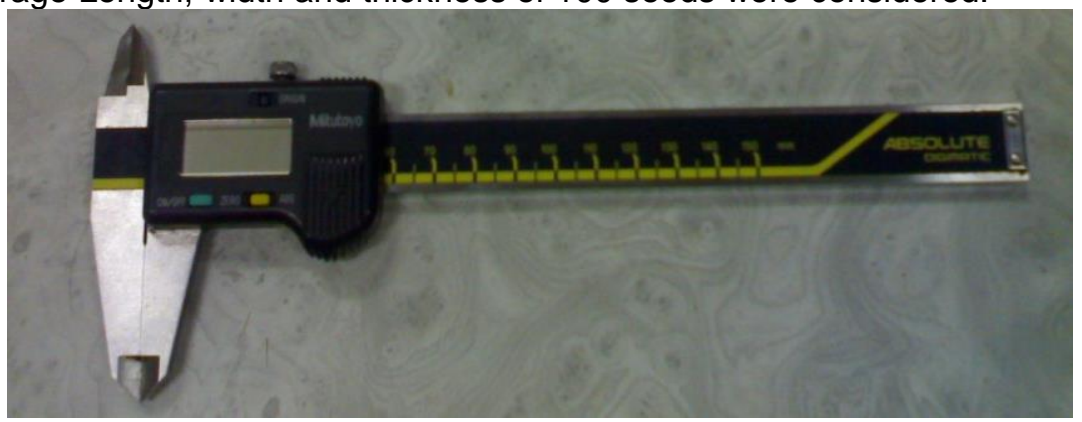

Figure (1): Digital vernier caliber

\section{C - Related characteristics of jojoba seeds:}

1- Geometric mean diameter $\left(D_{g}\right)$ :

The geometric mean diameter of jojoba seeds was calculated using the following equation (Mohsenin, 1984).

$\mathrm{D}_{\mathrm{g}}=\left(\mathrm{LWT}_{\mathrm{h}}\right)^{1 / 3}, \mathrm{~mm}$

2- Arithmetic mean diameter $\left(D_{a}\right)$ :

The arithmetic diameter of jojoba seeds was calculated using the following equation (Mohsenin, 1984).

$$
D_{a}=\left(L+W+T_{h}\right) / 3, m m
$$

\section{3- Seed volume $\left(\mathrm{V}_{\text {cal }}\right)$}

The calculated volume of seeds 'could be obtained from the following equation (Mohsenin, 1984).

$$
\mathrm{V}_{\text {cal }}=(\pi / 6) \mathrm{LWT}_{\mathrm{h}}
$$

\section{4- Sphericity (S):}

The sphericity percent of jojoba seeds was calculated from the following equation (Mohsenin, 1984).

$$
\mathrm{s}=\left[\left(\mathrm{LWT}_{\mathrm{h}}\right)^{1 / 3} / \mathrm{L}\right] \times(100)
$$

where, $0<s \leq 100 \%$.

\section{5- Frontal area $\left(A_{f}\right)$ :}

The frontal area of jojoba seed was calculated using the following formula (Mohsenin, 1984).

$$
A_{f}=(\pi / 4) L W, m^{2} \text {. }
$$

\section{6- Cross sectional area $\left(A_{t}\right)$ :}

The cross sectional area of jojoba seed was calculated using the following formula (Mohsenin, 1984).

7- Surface area $\left(A_{s}\right)$ :

$$
A_{t}=(\pi / 4)\left[\left(L+W+T_{h}\right) / 3\right]^{2}, \mathrm{~mm}^{2}
$$

The surface area of jojoba seeds was calculated using the following formula (Deshpande et al., 1993). 
$A_{s}=\pi D_{g 2}, m^{2}$

8- Surrounded surface area $\left(A_{s s}\right)$

The surrounded surface area was calculated from the following equation (El Raie et al., 1996).

$A_{s s}=(\pi / 2)\left(L+D_{g}\right)\left(D_{g}\right), m^{2}$

9- Aspect ratios $\left(\mathbf{R}_{1}, \mathbf{R}_{2}, \mathbf{R}_{3}\right)$

Three aspect ratios based on axial dimensions of seeds were developed as follows, (Tharwat, 2007).

$\mathrm{R}_{1}=(\mathrm{L} / \mathrm{W})$, decimal

$R_{2}=\left(L / T_{h}\right)$, decimal

$R_{3}=\left(W / T_{h}\right)$, decimal

10- Shape index of seeds (k)

Seeds shape index (k) was calculated using the measured values of the principal dimensions of seeds and was used to describe shape of seeds using the following equation, (Tharwat, 2007).

$$
\mathrm{K}=\mathrm{L} / \text { (W.Th) }^{0.5} \text {, decimal }
$$

\section{d- Mass of 100 seeds:}

The mass of 100 seeds was determined using an electronic digital balance model (MFD-K 1000920, Japan) with maximum reading of $200 \mathrm{~g}$ and accuracy of $0.01 \mathrm{~g}$. To determine the 100 seed mass, 10 samples of each of 100 seeds were weighted and the average of them was considered.

\section{e- Real density:}

The real density of jojoba seeds was calculated by dividing the weight of individual seed by its volume using toluene displacement methods as follows:

Where,

$$
R_{d}=W_{e} / V
$$

$R_{d}=$ Real density of the individual seed, $\mathrm{g} / \mathrm{cm}^{3}$.

$\mathrm{W}_{\mathrm{e}}=$ Weight of seed, $\mathrm{g}$.

f- Bulk density:

$\mathrm{V}=$ Volume of seed, $\mathrm{cm}^{3}$.

\section{At loose fill condition:}

Bulk density at loose seeds fill condition was determined by filling a known container volume with the seeds from a height of $150 \mathrm{~cm}$ at constant rate (Matouk, et al., 2004), then the weight of seeds bulk was determined $(3.25 \mathrm{~kg})$ and the bulk density was calculated as shown in equation (14).

Where:

Bulk density of seeds $=\mathrm{W} / \mathrm{V}_{\mathrm{b}}$

$\mathrm{W}=$ Weight of seeds bulk, $\mathrm{kg}$.

At vibrated fill condition:

$\mathrm{V}_{\mathrm{b}}=$ Volume of seeds bulk, $\mathrm{m}^{3}$.

Seeds bulk density at vibrated fill condition was determined by filling the same container with seeds under vibration using a laboratory seeds shaker figure (2) for two minutes. The bulk density of jojoba seeds was then calculated according equation (14). 


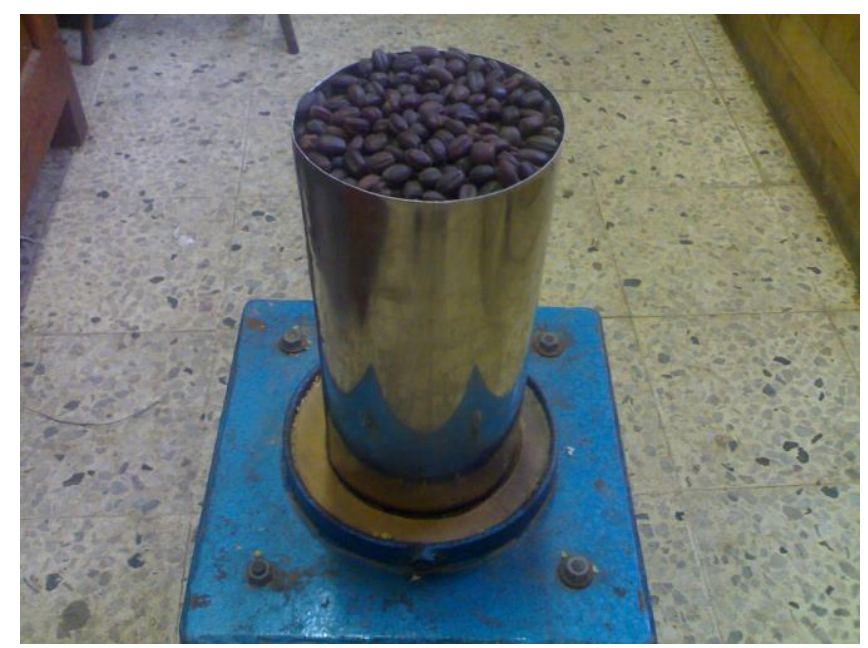

Figure (2): Bulk density meter with shaker.

\section{g- Porosity of jojoba seeds:}

Porosity of jojoba seeds was determined as a percentage of volume of inters - seed space into the volume of seeds bulk using porosity measuring device shown in figure (3). The apparatus was development by (Mohsenin, 1984) and fabricated according to (Matouk, et al., 2002).

The apparatus consists of two identical stainless-steel tanks sealed by compressed rubber covers. The first tank was connected to an air compressor, pressure reducer and control valves (1). The second tank was filled with seeds sample and connected to the control valve (2) and (3). A precise manometer was fixed to the main pipe for detecting the air pressure during different stages of measurement. Figure (3) shows the apparatus used for measuring seeds porosity.

Jojoba seeds were filled in tank (2) before closing both of valves (2 and 3). The air was supplied in tank (1), when a suitable manometer displacement was achieved, valve (1) was closed and the steady state pressure $\left(p_{1}\right)$ was recorded. After that, valve (2) was opened keeping valves (1 and 3) closed. A steady state manometer reading $\left(p_{2}\right)$ was recorded then, the porosity of jojoba seeds was found by the following formula:

Where,

$$
P=\left(P_{1}-P_{2}\right) / p_{2}
$$

$\mathrm{P}=$ porosity of seeds, $\%$

$\mathrm{P}_{1}=\quad$ steady state pressure inside tank (1), bar

$\mathrm{P}_{2}=\quad$ steady state pressure in both tank (1) and (2) together, bar 


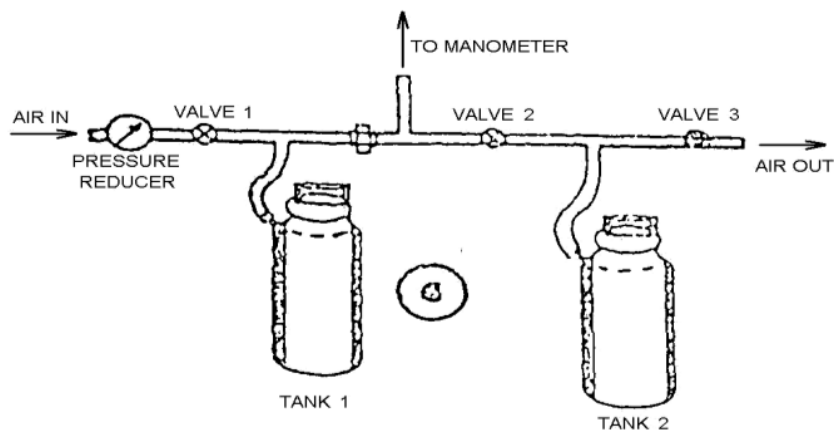

Figure (3): laboratory apparatus used for measuring jojoba seeds porosity.

\subsubsection{Mechanical Properties:}

\section{a- Seeds repose angle:}

Angle of repose apparatus designed by (Matouk, et. al., 2006 a) was used for the experimental work. The apparatus consists of a wooden box with inner dimensions of $18 \times 18 \times 20 \mathrm{~cm}$, three transparent plastic sided (left, right and front sides), where the front side is sliding up and down. Wooden parallelogram with a base fixed in the protractor was used to measure the angle between the base and the inclined of the formed cone due to a free side fall of the seeds as shown in figure (4).

In this test each seeds sample was taken randomly and then poured in the wooden box of the apparatus until completely filling the box $(1.25 \mathrm{~kg})$. The surface of the box is carefully leveled and the transparent sliding side is quickly taken up to give a chance for the seeds to flow down under natural slope forming an inclined angle between the box side and the horizontal surface of the table.

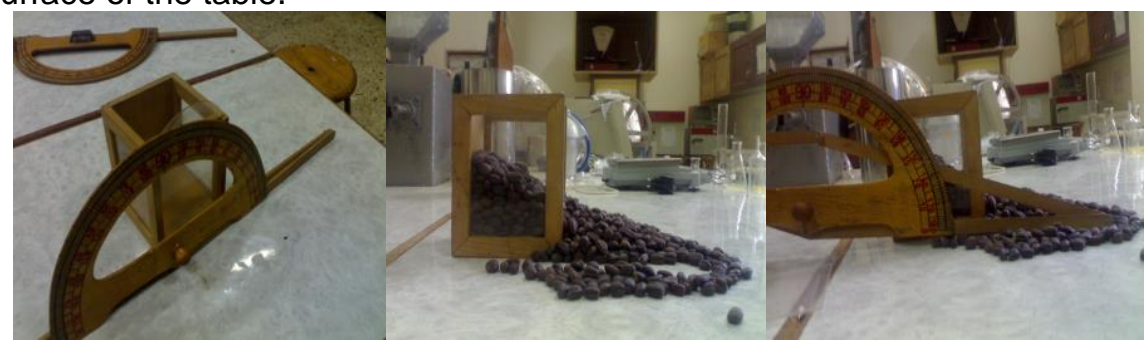

Figure (4): Repose angle meter.

b- Hardness, shear and crushing force of seeds:

Hardness, shear and crushing force meter model (FGN-50, USA) with an accuracy of $0.01 \mathrm{~N}$, and a digital LCD was used for measuring seed hardness, shear and crushing force as follows.

\section{1 - Seed hardness:}

For measuring seed hardness, a seed was pressed by the conical end of the meter, while the digital reading was increased with the increasing of the pressure on the seed until it has been cracked. 
At this point the displayed reading means seed hardness described by (Matouk, et al., 2006 b). It should be mentioned here that each tested sample was represented by 10 seeds and only one reading was recorded for each seed.

2 - Seed shear force and shear stress:

Shear force was measured at both longitudinal and transverse axis. The conical end of the meter was changed to shearing edge (straight sharp edge), as shown in figure (5) and the previously mentioned procedure was used for measuring shear force at both seed axis.

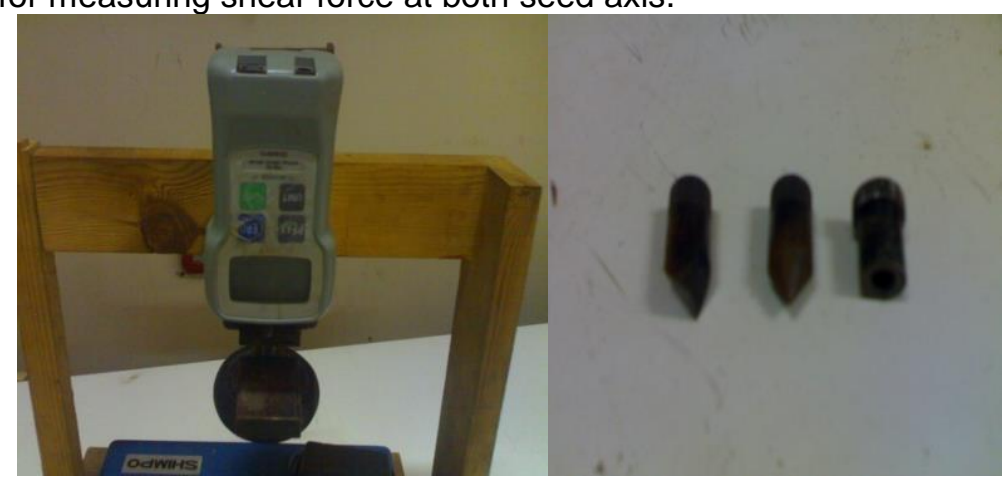

Figure (5): Digital hardness and shear force gauge.

The average of 10 reading of shear force at the longitudinal axis was used for calculating shear stress at this axis using the following equation:

$$
S_{L}=F_{L} / A_{L}
$$

Where:

$S_{L}$ : shear stress at seed longitudinal axis

$F_{L}$ : shear force at seed longitudinal axis

$A_{L}$ : cross section area of shear at seed longitudinal axis

The value of $A_{L}$ for jojoba seed could be calculated using the following relationship:

$$
A_{L}=(\pi / 4) \text {. L. } T_{h}
$$

Also, the average of 10 reading shear force at transverse axis was used for calculating the shear stress at this axis using the following equation:

Where,

$$
S_{w}=F_{w} / A_{w}
$$

$\mathrm{S}_{\mathrm{w}}$ : shear stress at seed transverse axis

$\mathrm{F}_{\mathrm{w}}$ : shear force at seed transverse axis

$A_{w}$ : cross section area of shear at seed transverse axis

The value of $A_{w}$ for jojoba seed could be calculated using the following relationship:

$$
A_{L}=(\pi / 4) \cdot W \cdot T_{h}
$$

\section{3 - Seed crushing force}

Crushing force as a very important characteristic in oil extraction process was measured at both longitudinal and transverse axis. The conical end of the meter was changed to flat edge, and following the same procedure of hardness measurement. 


\section{RESULTS AND DISCUSSION}

\section{Physical properties of jojoba seeds:}

Determinations of the main principal dimensions of jojoba seeds are very important for describing their technological characteristics and effectiveness in many respects. The dimensions of jojoba seeds (length, width and thickness) shape index, seed volume, frontal area, sphericity, mass of 100 seeds, real density and bulk density were measured and presented in tables (1).

Table (1): Physical properties of jojoba seeds:

\begin{tabular}{|c|c|c|c|c|c|c|}
\hline Characteristics & Unit & $\begin{array}{l}\text { Number of } \\
\text { replication }\end{array}$ & $\begin{array}{l}\text { Mean } \\
\text { value }\end{array}$ & $\begin{array}{l}\text { Max. } \\
\text { value }\end{array}$ & $\begin{array}{c}\text { Min. } \\
\text { value }\end{array}$ & $\begin{array}{l}\text { Standard } \\
\text { deviation }\end{array}$ \\
\hline Length & $\mathrm{mm}$ & 100 & 16.95 & 18.82 & 13.52 & 0.91 \\
\hline Width & $\mathrm{mm}$ & 100 & 13.13 & 14.67 & 10.84 & 0.87 \\
\hline Thickness & $\mathrm{mm}$ & 100 & 11.78 & 13.30 & 9.08 & 0.74 \\
\hline Volume & $\mathrm{mm}^{3}$ & 100 & 1374.62 & 1711.11 & 945.92 & 160.73 \\
\hline $\begin{array}{l}\text { Geometric } \\
\text { diameter }\end{array}$ & $\mathrm{mm}$ & 100 & 13.74 & 14.80 & 12.15 & 0.55 \\
\hline $\begin{array}{l}\text { Arithmetic } \\
\text { Diameter }\end{array}$ & $\mathrm{mm}$ & 100 & 13.95 & 14.95 & 12.43 & 0.53 \\
\hline Frontal area & $\mathrm{mm}^{2}$ & 100 & 174.80 & 203.49 & 135.63 & 15.01 \\
\hline $\begin{array}{l}\text { Arithmetic cross } \\
\text { sectional area }\end{array}$ & $\mathrm{mm}^{2}$ & 100 & 153.14 & 175.62 & 121.28 & 11.43 \\
\hline Sphericity & $\%$ & 100 & 81.19 & 95.72 & 67.88 & 4.32 \\
\hline Shape index & decimal & 100 & 1.37 & 1.78 & 1.06 & 0.11 \\
\hline Surface area & $\mathrm{mm}^{2}$ & 100 & 593.82 & 688.11 & 463.68 & 46.72 \\
\hline $\begin{array}{l}\text { Surrounded } \\
\text { surface area }\end{array}$ & $\mathrm{mm}^{2}$ & 100 & 663.04 & 758.40 & 533.39 & 48.71 \\
\hline Porosity & $\%$ & 3 & 44.88 & 0.50 & 0.42 & 0.03 \\
\hline R1 & decimal & 100 & 1.30 & 1.67 & 1.02 & 0.11 \\
\hline $\mathrm{R} 2$ & decimal & 100 & 1.45 & 2.04 & 1.11 & 0.14 \\
\hline R3 & decimal & 100 & 1.12 & 1.31 & 1.00 & 0.08 \\
\hline $\begin{array}{l}\text { Mass of } 100 \\
\text { seeds }\end{array}$ & g & 100 & 103.80 & 109.20 & 99.15 & 3.12 \\
\hline Real density & $\mathrm{kg} / \mathrm{m}^{3}$ & 5 & 976.86 & 989.35 & 841.33 & 61.89 \\
\hline $\begin{array}{l}\text { Bulk density } \\
\text { at loose seed fill }\end{array}$ & $\mathrm{kg} / \mathrm{m}^{3}$ & 5 & 602.10 & 629.07 & 564.94 & 33.16 \\
\hline $\begin{array}{l}\text { Bulk density } \\
\text { at vibrated seed fill }\end{array}$ & $\mathrm{kg} / \mathrm{m}^{3}$ & 5 & 630.33 & 644.16 & 615.87 & 11.31 \\
\hline
\end{tabular}

As shown in (table 1), the principal dimensions of jojoba seeds length, width and thickness recorded values of $(16.95,13.13$ and $11.78 \mathrm{~mm})$ respectively.

Meanwhile, the volume of seeds recorded a mean value of (1374.62 $\mathrm{mm}^{3}$ ), geometric diameter of $(13.74 \mathrm{~mm})$, arithmetic diameter of $(13.95 \mathrm{~mm})$, frontal area of $\left(174.80 \mathrm{~mm}^{2}\right)$, and arithmetic cross sectional area of $(153.14$ $\mathrm{mm}^{2}$ ).

In (table 1) the sphericity of seeds and ranged from (67.88 to 95.72 $\%$ ) with a mean value of $81.19 \%$, This results indicate that , jojoba seeds is quite close to the shape of a sphere which means that a sieving or separation machine with circular holes is suitable for separation process of jojoba seeds. 
During unloading the seeds will roll a way too far from intended unloading spot.

On the other hands, the Porosity of seeds recorded a mean value of $(44.88 \%)$, shape index of (1.37), surface area of $\left(593.82 \mathrm{~mm}^{2}\right)$ and surrounded surface area of $\left(663.04 \mathrm{~mm}^{2}\right)$. Also, the average real density of jojoba seeds was $976.86 \mathrm{~kg} / \mathrm{m}^{3}$ and the average values of bulk density which consider important for handling process were 602.10 and $630.33 \mathrm{~kg} / \mathrm{m}^{3}$ at loosely and vibrated fill conditions respectively.

The table also shows that, the average jojoba mass was $1.03 \mathrm{~g}$ compared with $0.068 \mathrm{~g}$ for sunflower, $0.181 \mathrm{~g}$ for soybean and $0.003 \mathrm{~g}$ for canola as determined by (Tharwet, 2007). Thus, the jojoba seed has a bigger mass, that indicate higher percentage of oil in comparison with the previously mentions seeds.

Meanwhile, the three aspect ratios of jojoba seeds recorded mean values of $(1.30,1.45,1.12)$ for $\left(R_{1}, R_{2}\right.$ and $\left.R_{3}\right)$ respectively.

Figure (6) illustrates the frequency distribution curves of seed dimensions at moisture content of $(7 \pm 1 \%)$ (d.b). As shown in the figure a trend towards a normal distribution was detected for all dimensions. This means that $85 \%$ of jojoba seeds had lengths between 15 and $17 \mathrm{~mm}, 93 \%$ had width between 12 and $14 \mathrm{~mm}$ and $97 \%$ had thickness between 10 and $12 \mathrm{~mm}$.

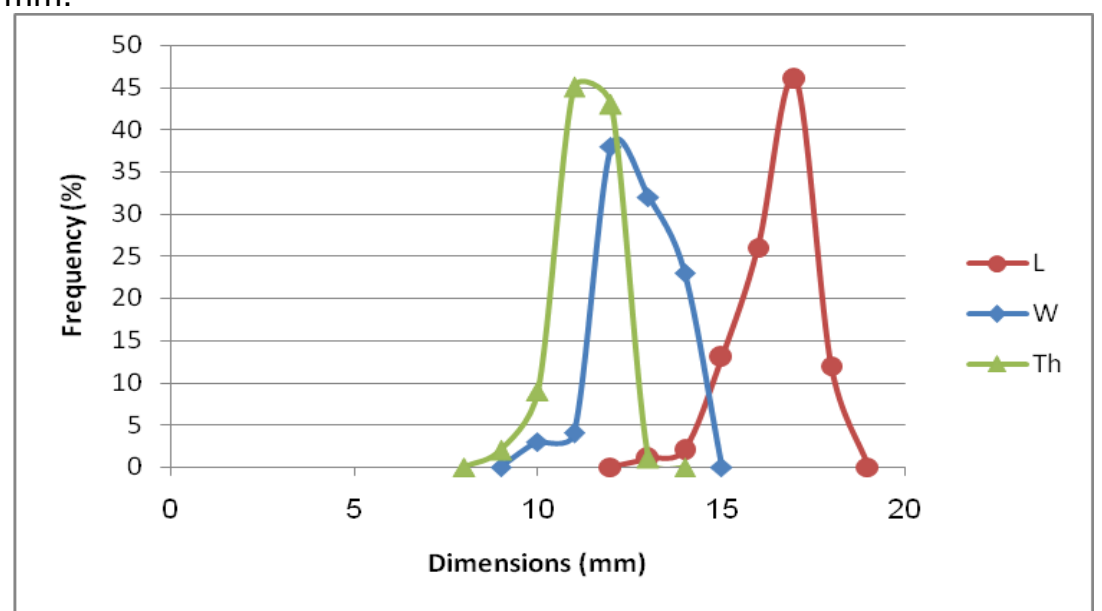

Fig (6): Frequency distribution curves for dimensions of jojoba seeds at $(7 \pm 1 \%)(d . b)$.

General expressions shown in (table 2) were used to describe the relationships between the average principal dimensions of jojoba seeds at ( 7 $\pm 1 \%$ ) (d.b.) moisture content as follow:

The coefficient of determination shows that the width, thickness, volume, geometric diameter, arithmetic diameter, frontal Area, arithmetic cross sectional area, surface area, surrounded surface area, sphericity, shape index and mass of one seed are highly correlated to each other 
Matouk, A. M. et al.

Table (2): General expressions describing the relationships between the length and the physical properties of jojoba seeds.

\begin{tabular}{|l|c|l|c|}
\hline \multicolumn{1}{|c|}{ Characteristics } & Symbol & \multicolumn{1}{c|}{ Equation } & $\begin{array}{c}\text { Coefficient of } \\
\left.\text { determination, } \mathbf{R}^{\mathbf{2}}\right)\end{array}$ \\
\hline Width & $\mathrm{W}$ & $\mathrm{L}=1.289 \mathrm{~W}$ & 0.9872 \\
\hline Thickness & $\mathrm{T}_{\mathrm{h}}$ & $\mathrm{L}=1.4368 \mathrm{~T}_{\mathrm{h}}$ & 0.9837 \\
\hline Volume & $\mathrm{V}$ & $\mathrm{L}=0.0123 \mathrm{~V}$ & 0.9487 \\
\hline Geometric diameter & $\mathrm{d}_{\mathrm{g}}$ & $\mathrm{L}=1.2331 \mathrm{~d}_{\mathrm{g}}$ & 0.9944 \\
\hline Arithmetic diameter & $\mathrm{d}_{\mathrm{a}}$ & $\mathrm{L}=1.2142 \mathrm{~d}_{\mathrm{a}}$ & 0.9958 \\
\hline Frontal Area & $\mathrm{A}_{\mathrm{f}}$ & $\mathrm{L}=0.0968 \mathrm{~A}_{\mathrm{f}}$ & 0.9838 \\
\hline $\begin{array}{l}\text { Arithmetic cross } \\
\text { sectional area }\end{array}$ & $\mathrm{A}_{\mathrm{t}}$ & $\mathrm{L}=0.1105 \mathrm{~A}_{\mathrm{t}}$ & 0.9826 \\
\hline Surface area & $\mathrm{A}_{\mathrm{s}}$ & $\mathrm{L}=0.0285 \mathrm{~A}_{\mathrm{s}}$ & 0.9773 \\
\hline $\begin{array}{l}\text { Surrounded surface } \\
\text { area }\end{array}$ & $\mathrm{A}_{\mathrm{ss}}$ & $\mathrm{L}=0.0255 \mathrm{~A}_{\mathrm{ss}}$ & 0.9869 \\
\hline Sphericity & $\mathrm{S}$ & $\mathrm{L}=0.2086 \mathrm{~S}$ & 0.9925 \\
\hline Shape index & $\mathrm{K}$ & $\mathrm{L}=12.371 \mathrm{~K}$ & 0.9826 \\
\hline Mass of one seed & $\mathrm{M}$ & $\mathrm{L}=16.32 \mathrm{M}$ & 0.9940 \\
\hline * (Length of seed). & & & \\
\hline
\end{tabular}

\section{Mechanical properties of jojoba seeds:}

Repose angle, seed hardness, shear force, and crushing force of seeds were measured and presented in table (3).

Table (3): Mechanical properties of jojoba seeds.

\begin{tabular}{|l|c|c|c|c|c|c|}
\hline \multicolumn{1}{|c|}{ Characteristics } & Unit & $\begin{array}{c}\text { Number of } \\
\text { replications }\end{array}$ & $\begin{array}{c}\text { Mean } \\
\text { value }\end{array}$ & $\begin{array}{c}\text { Max. } \\
\text { value }\end{array}$ & $\begin{array}{c}\text { Min } \\
\text { value }\end{array}$ & $\begin{array}{c}\text { Standard } \\
\text { Deviation (S.D) }\end{array}$ \\
\hline Repose angle & Degree & 5 & 29.00 & 29.00 & 29.00 & 0.00 \\
\hline $\begin{array}{l}\text { Seed hardness } \\
\begin{array}{l}\text { Shear force at the } \\
\text { longitudinal axis }\end{array}\end{array}$ & $\mathrm{N}$ & 10 & 153.19 & 158.60 & 150.20 & 2.62 \\
\hline $\begin{array}{l}\text { Shear force at the } \\
\text { transverse axis }\end{array}$ & $\mathrm{N}$ & 10 & 207.45 & 254.30 & 165.40 & 29.47 \\
\hline $\begin{array}{l}\text { Crushing force at the } \\
\text { longitudinal axis }\end{array}$ & $\mathrm{N}$ & 10 & 302.95 & 385.40 & 202.90 & 58.43 \\
\hline $\begin{array}{l}\text { Crushing force at the } \\
\text { transverse axis }\end{array}$ & $\mathrm{N}$ & 10 & 295.25 & 367.60 & 266.30 & 32.29 \\
\hline
\end{tabular}

As shown in table (3), jojoba seeds repose angle, which considered as one of the mechanical properties needed for design of material handling system and storage facilities recorded a mean value of $29^{\circ}$.

Seed hardness, shear force at the longitudinal and transverse axis and the crushing force of seeds at the longitudinal and the transverse axis which are also considered important properties in designing vertical storage systems and in pressing process during oil extraction. As shown in table (3), the above mentioned properties recorded mean values of $153.19 \mathrm{~N}, 111.78$ $\mathrm{N}, 207.45 \mathrm{~N}, 302.95 \mathrm{~N}$ and $295.25 \mathrm{~N}$ respectively.

\section{CONCLUSIONS}

The results of the studied physical and mechanical properties of jojoba seeds can be summarized as follows: 
1- The dimensions of jojoba seeds including length, width and thickness recorded values of $(16.95,13.13$ and $11.78 \mathrm{~mm})$ respectively.

2- Jojoba seed recorded volume of $\left(1374.62 \mathrm{~mm}^{3}\right)$, geometric diameter of $(13.74 \mathrm{~mm})$, arithmetic diameter of $(13.95 \mathrm{~mm})$, frontal area of $(174.80$ $\left.\mathrm{mm}^{2}\right)$, arithmetic cross sectional area of $\left(153.14 \mathrm{~mm}^{2}\right)$, and a sphericity of $(81.19 \%)$.

3 - The porosity of seeds recorded a mean value of (44.88\%), shape index of (1.37), surface area of $\left(593.82 \mathrm{~mm}^{2}\right)$ and surrounded surface area of $\left(663.04 \mathrm{~mm}^{2}\right)$.

4- The average real density of jojoba seeds was $976.86 \mathrm{~kg} / \mathrm{m}^{3}$. While, the average values of bulk density were 602.10 and $630.33 \mathrm{~kg} / \mathrm{m}^{3}$ under loosely and vibrated fill conditions respectively.

5- The average repose angle of jojoba seeds recorded a value of $29^{\circ}$, seed hardness of $153.19 \mathrm{~N}$, shear force of $111.78 \mathrm{~N}$ at the longitudinal axis and $207.45 \mathrm{~N}$ at the transverse axis.

6- The crushing forces of jojoba seeds were 302.95 and $295.25 \mathrm{~N}$ at the longitudinal and the transverse axis respectively. While, the recorded average of seeds porosity was about $44.88 \%$.

7- Weight of hundred seeds ranged from (99.15 to $109.20 \mathrm{~g}$ ) with an average was $103.70 \mathrm{~g}$.

\section{REFERENCES}

Deshpande, S., Bat, S; and T.P. Ojha, (1993 ). physical properties of sybean. J. Agric. Engng. Res., (56): 89-98.

El Raie, A. E; Hendawy, N. A; and Taib, A.Z., (1996) Study of physical and engineering properties for some agricultural products. Misr. J. Agric Engng. Vol. 13 (1): $211-226$.

Hogan, L.;G. W. Lee; D. A. palzkill ; and W. R. Feldman (1980). Jojoba: A new horticultural crop for arid regions. Hort. science, vol. 15 (2), p. 114.

Kadharmestan C., L, Nguyen, G, Mikhaylenko; and G. M. Hyde, (1997). Rapeseed/Canola Oil Seed Extraction. Semester Project Assignment Phase 3.Dept. of Biosystem Engnge., Washington State Unive.

Matouk, A.M. ; S. M Radwan; A.S . Hamam; G. H .El sayed; M. M . El- Kholy; and T. R . Owies, (2002). Study of physical properties and characteristics of some agricultural crops for development and designing harvesting and handling equipment and systems. Ministry of Higher Education and Scientific Research - Academy of Scientific Research and Technology. Agric. Engng. Dept. Fac. Of Agric. Mansoura Univ.

Matouk A. M., S. M. Radwan, M. M. El-Kholy and T. R. Owies, (2004). Determination of grains density and porosity for some cereal crops Misr J. Agric. Engng. Vol. 21 (3): 623-641.

Matouk, A.M. ; A.S . Hamam ; M. M . El- Kholy ; and S. M Radwan,; (2006a). Effect of grain moisture content on repose angle of some varieties of cereal crops. J. of Agric. Sci., Mansoura Univ. Vol.31 (5): 2957-2964. 
Matouk, A.M. ; A.S . Hamam ; S. M Radwan ; and T.R. Owies , (2006 b ) . Effect of moisture content on mechanical properties of some cereal grain. J. of Agric. Sci., Mansoura Univ. Vol.23 (1): January 2006.

Milthorpe, P. L., (1998). Jojoba in The new rural industries. (Ed K.W.Hyde) RIRDC, Canberra. 384-9.

Mohsenin, N. N., (1984). Physical properties of plant and animal materials. Gordon and Breach Sc.pub., N.Y.pp. 734.

Owies, T. R., (1995). Physical and engineering properties of cereal grain and their relation to the selection and design of cleaning devices. Unpublished M.S. Thesis. Agric. Engng. Dept. Fac. Of Agric. Cairo Univ.

Tharwat, A. M., (2007). Effect of some physical, mechanical and thermal properties on design parameters of handling and processing machinery of some oil seeds . Un-published P.hd Thesis , Agric. Engng. Dept. Fac. Of Agric. Mansoura Univ

Tobares, L., M. Frati, C. Guzman and D. Maestri. (2004). Agronomical and chemical traits as descriptors for discrimination and selection of jojoba (Simmondisia chinensis (Link) Schneider) clones. Industrial crops and products (19): 107- 111.

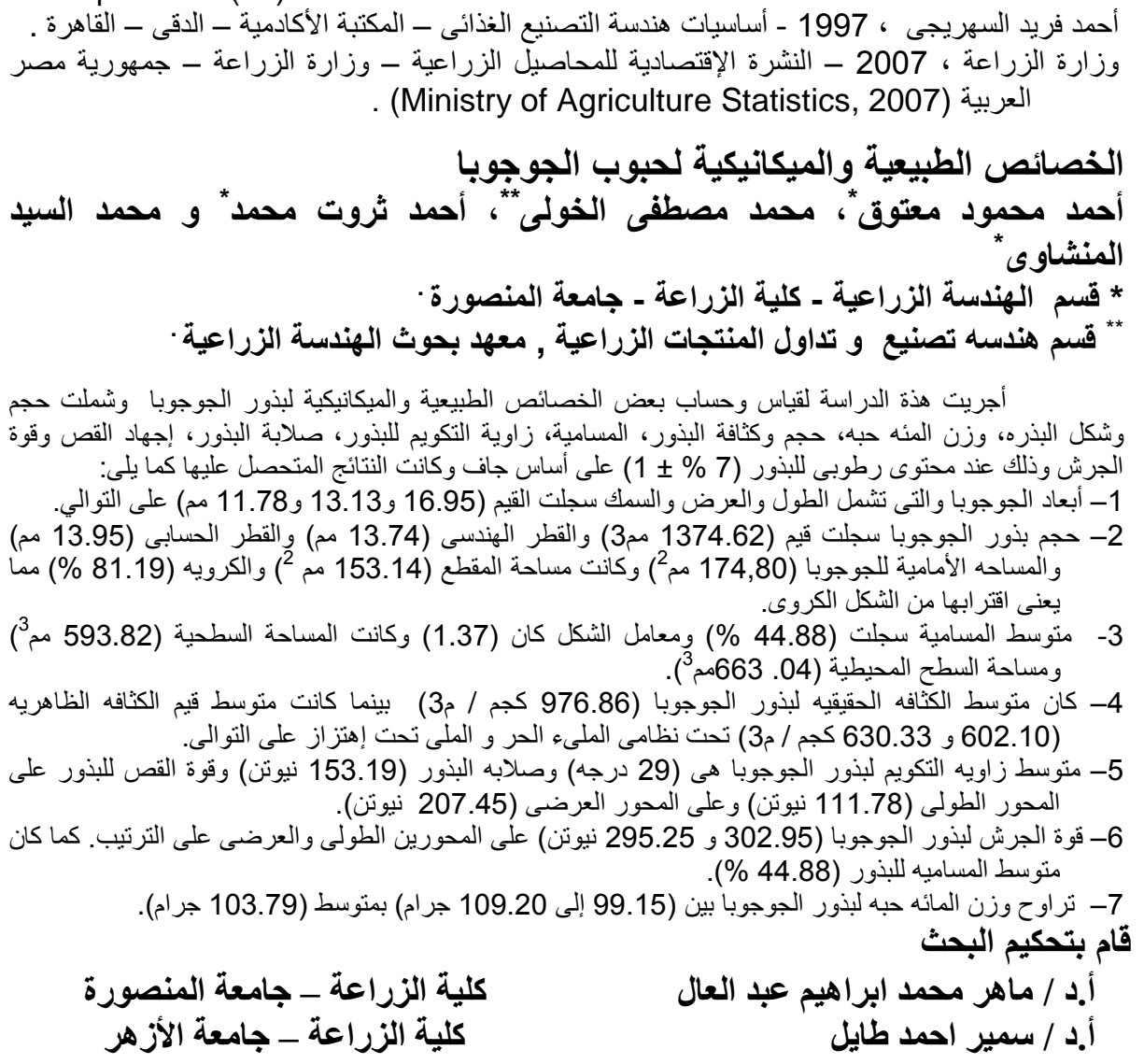

